\title{
Terapia génica en el cáncer de próstata. ¿Es posible una vacuna?
}

\author{
Gómez Pérez L*, Delgado Oliva FJ*, Vera Donoso CD**, Jiménez Cruz JF**, \\ Hernández Andreu JM***. \\ *Servicio de Urología. Hospital de Elche **Servicio de Urología Hospital Universitario La Fe. Valencia. \\ ***Departamento de Biología Molecular. Universidad Cardenal Herrera - CEU. Valencia.
}

Actas Urol Esp. 2007;31(7):705-713

\section{RESUMEN}

TERAPIA GÉNICA EN EL CÁNCER DE PRÓSTATA: ¿ES POSIBLE UNA VACUNA?

Introducción: Debido a las limitaciones existentes en el tratamiento del cáncer de próstata en estadios avanzados, se precisan nuevas estrategias de tratamiento para estos pacientes. El desarrollo de la biología molecular en el campo del cáncer de próstata, ha proporcionado un mayor conocimiento de las alteraciones más comunes a nivel del ADN de las células cancerígenas, que podrían ser utilizadas como dianas terapéuticas. En este artículo se han revisado los conceptos actuales en el campo de la terapia génica, las alteraciones génicas más frecuentes en el cáncer de próstata y posibles estrategias de tratamiento.

Palabras clave: Terapia génica. Cáncer de próstata. Vectores virales.

\section{ABSTRACT \\ GENE THERAPY: IS POSSIBLE A VACCINE FOR PROSTATE CANCER?}

Background: New approaches for prostate cancer are needed due to limitations of current therapies for the treatment in advanced stages of the disease. In fact, there is no effective treatment for these patients. Development in molecular biology research on prostate cancer has improved the knowledge of common alterations encoded in DNA sequence, which may be useful as targets for prostate cancer approach. In this review we give an overview of current gene therapy concepts, the most common gene alterations in prostate cancer and the gene therapy treatment strategies.

Keywords: Gene therapy. Prostate cancer. Viral vectors.

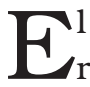
cáncer de próstata (CP) se ha convertido recientemente en el tumor diagnosticado con más frecuencia en el hombre y es la segunda causa de mortalidad en varones americanos. A pesar de los avances realizados en el diagnóstico y tratamiento del $\mathrm{CP}$, del $27 \%$ al $53 \%$ de los pacientes con enfermedad clínicamente localizada no son curados mediante los tratamientos disponibles actualmente y otro $19 \%$ presentan enfermedad localmente avanzada en el momento del diagnóstico ${ }^{1}$. Actualmente el pronóstico de los pacientes con cáncer de próstata avanzado o con metástasis es desolador a pesar de la respuesta inicial a la deprivación androgénica. En estos casos, el CP es básicamente resistente a los esquemas de quimioterapia sistémica, mientras que la radioterapia sólo tiene utilidad como terapia paliativa. Por este motivo, el desarrollo de nuevos tratamientos, como la terapia génica, es un objetivo prioritario.

Los estudios citogenéticos actuales se basan en la hipótesis de que el cáncer es el resultado de de alteraciones cromosómicas que afectan a genes que podemos definir como críticos. Los cánceres, 
incluido el de próstata, se desarrollan en una serie de etapas que asocian alteraciones genéticas, lo que se traduce en fenómenos como proliferación celular, seguido de transformación maligna de estas células y diseminación metastásica. Se ha intentado establecer un patrón de alteraciones cromosómicas ${ }^{2}$ que definan esta progresión tumoral aunque debido a la heterogenicidad histológica del CP y los sucesivos hallazgos de genes implicados, no existe un patrón común que defina claramente las etapas de este cáncer (Fig. 1).

Basándonos en el conocimiento de las alteraciones cromosómicas del CP (delecciones, ampliaciones, mutaciones...) y el avance tecnológico, sería lógico intentar corregir dichas alteraciones genéticas para curar la enfermedad. Surge así el concepto de la terapia génica (TG), que consiste en la transferencia y posterior expresión de material genético con fines terapéuticos.

Existen diferentes estrategias ${ }^{3}$ de tratamiento en TG como:

- Terapia génica de corrección, que intentaría restaurar la función normal de un gen mutado o deleccionado (normalmente genes supresores tumorales) favoreciendo la reparación genética o muerte celular, o interferir la actividad de genes promotores de actividad tumoral (oncogenes).

- Terapia génica citorreductora mediante la transferencia de un gen que provoque la muerte de células tumorales (genes suicidas).

- Terapia génica de inmunodulación, aquella capaz de inducir la expresión de genes que incrementen la respuesta inmune contra células tumorales.

\section{VECTORES PARA LA TERAPIA GÉNICA}

Para que la TG sea efectiva, es importante tanto la elección de los genes adecuados para su manipulación, como el tipo vehículo que utilizaremos para transportar los genes seleccionados a las células diana, ya que la TG más sofisticada no sirve de nada a menos que los genes puedan ser dirigidos a una fracción importante de las células tumorales ${ }^{4}$. El vector ideal sería aquél que siendo específico para la célula diana, fuera capaz de transferir los genes de interés de un modo eficaz para su posterior expresión. No debe ser tóxico ambiental, ni para el paciente, no mutagénico, ni inmunogénico e idealmente producido en altas concentraciones a bajo coste ${ }^{5}$. Este tipo de vector ideal no existe hasta la fecha. Los vectores utilizados se dividen en dos grupos, virales y no virales.

\section{Vectores virales}

Son los vectores utilizados en la mayoría de los ensayos clínicos de TG, ya que son capaces de integrarse en las células humanas y expresar sus genes de un modo eficaz. La principal manipulación que debe realizarse en este tipo de vectores radica en eliminar las regiones del genoma viral necesarias para su replicación y patogénesis. Las regiones del genoma eliminadas pueden entonces ser reemplazadas por aquellos genes terapéuticos que deseemos transferir. Las manipulaciones génicas no alterarian el tropismo del virus por la célula diana, ni su capacidad de expresarse ${ }^{6}$. Los más utilizados han sido retrovirus, adenovirus,

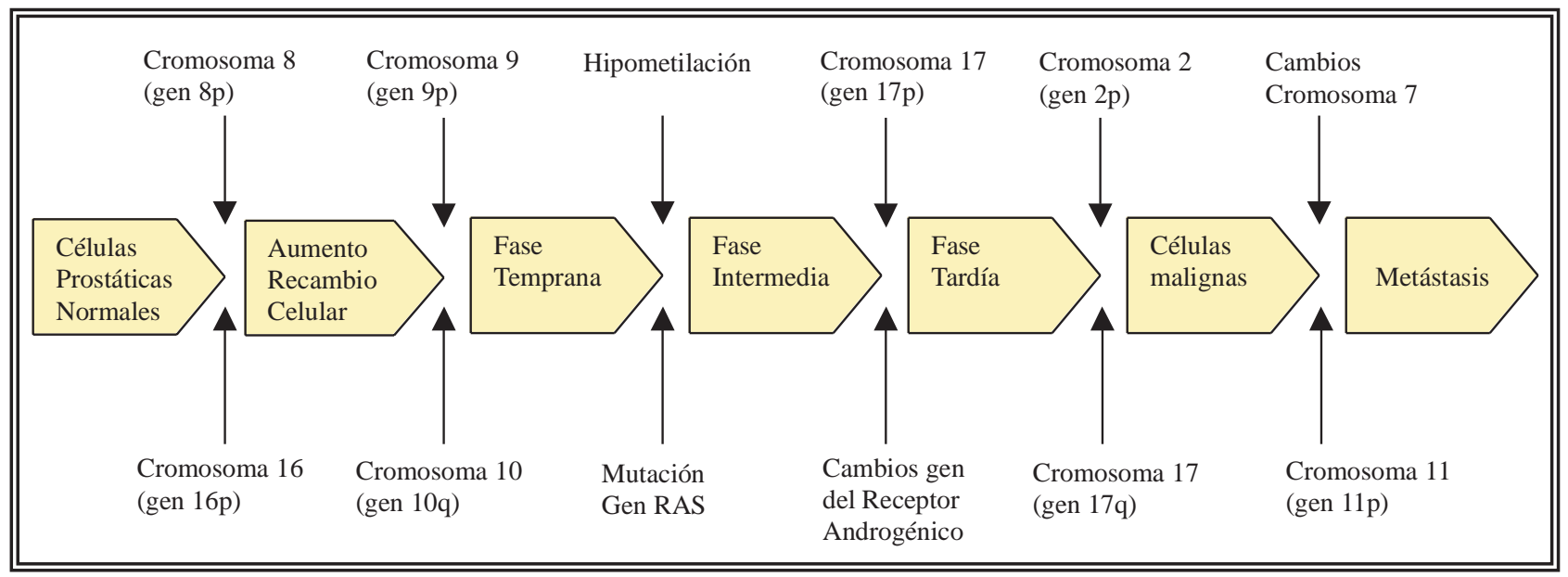

FIGURA 1. Posible patrón de alteraciones cromosómicas que definen la progresión tumoral. 
adenovirus asociados, virus herpes simple y pox virus, aunque otro tipo de vectores han sido investigados, como los reovirus ${ }^{7}$, virus de la enfermedad de Newcastle $^{7}$ y virus de la estomatitis vesicular ${ }^{8}$.

\section{Retrovirus}

Son RNA virus de cadena simple, capaces de introducirse en la célula diana tras unirse a receptores específicos de membrana, a través de su cubierta proteica. Una vez en el citoplasma de la célula, el RNA viral se transcribe en DNA de doble cadena mediante la enzima transcriptasa inversa que fabrica el propio virus. Este DNA debe pasar al núcleo, lo que ocurre en las células en división únicamente. Posteriormente se integra en el genoma huésped, expresándose el material genético transducido durante largo tiempo.

Los retrovirus utilizados en la TG están manipulados, de forma que conservan su capacidad infectiva, pero son incapaces de replicarse eficazmente. Debido a la pobre penetración y difusión de los retrovirus tras la inyección directa en el tejido prostático, así como su capacidad para producir mutagénesis y potencial desarrollo de enfermedades malignas, los retrovirus no suelen ser utilizados como terapia génica en el CP. Por otra parte, el genoma de los retrovirus es pequeño, lo que limita la cantidad de material genético que puede transportar ${ }^{9}$.

De la familia de los retrovirus, los lentivirus (como el de la inmunodeficiencia humana) presentan ciertas ventajas, como la capacidad de integrarse en el genoma, tanto si las células están en división como si no. Sin embargo, los aspectos relativos a la seguridad, han limitado mucho su utilización ${ }^{10}$.

\section{Adenovirus}

Son virus DNA de doble cadena. Existen más de 40 serotipos reunidos en 6 grupos (de la A a la F). Los más estudiados pertenecen al grupo C (serotipos Ad2 y Ad5) ${ }^{11}$. Son los vectores virales más empleados en el CP en estudios clínicos, debido a la facilidad de su manipulación in vitro, posibilidad de producir virus purificados en altas concentraciones y capacidad de transducción eficiente. Se traslocan al núcleo, tanto de células en división como quiescentes y su DNA no es incor- porado al genoma del huésped, por lo que minimizan el riesgo de mutagénesis y desarrollo de enfermedades malignas.

Una de las principales desventajas es que la expresión del DNA insertado es temporal y además desencadena una respuesta inmune celular y humoral por parte del huésped, que elimina tanto el vector como la célula transducida. La respuesta inmune es más rápida tras las siguientes inyecciones prostáticas del vector. Estos aspectos limitan la expresión del material genético insertado ${ }^{5}$. Ha sido posible incrementar la duración de la expresión génica mediante la utilización de inmunosupresores o agentes que bloquean linfocitos $\mathrm{T}$ citotóxicos ${ }^{12}$.

Se han desarrollado nuevos adenovirus a los que se les ha quitado la mayoría de la secuencia genética de su genoma. Estos vectores (adenovirus "vacíos") tienen la ventaja de poder transportar largos fragmentos de DNA de más de 35Kd, en comparación con los vectores tipo adenovirus (8Kd) y no expresan proteínas víricas, lo que limita la capacidad de generar respuesta inmune ${ }^{13}$ por parte del huésped.

Existe la posibilidad teórica de diseminación local de los adenovirus inyectados al aparato genitourinario, en particular a los testes, donde teóricamente podría insertarse en la línea germinal de los espermatozoides y pasar a siguientes generaciones en caso de descendencia, aunque este hecho no ha sido demostrado ${ }^{14}$.

\section{Adenovirus asociados}

Son DNA virus de cadena simple con una capacidad de replicación deficiente. Este hecho le otorga un aspecto característico y es que al ser un virus deficiente, requiere la coinfección con otro virus (virus helper: herpes virus o adenovirus) para replicarse. Es capaz de pasar al núcleo de las células con independencia de que se encuentren en división o no, manteniéndose estable una vez integrado en su genoma ${ }^{4}$.

Una de sus desventajas es que una vez manipulado, pierde su capacidad de integrarse en el genoma huésped en un lugar específico (19q13.4), lo cual incrementa su capacidad de inducir mutagénesis de inserción ${ }^{15}$. Su capacidad para transportar genes es pequeña (5kbp) y los virus helper pueden contaminar las preparaciones para su uso clínico. 


\section{Herpes simple}

Son virus DNA de doble cadena, cuyo uso está limitado por su potencial patogénico, transducción poco eficaz y una expresión pasajera de los genes transportados. Sin embargo poseen algunas cualidades importantes en el ámbito de la terapia génica. Una vez manipulados son vectores con alta capacidad de transporte $(35 \mathrm{~kb})$, con mayor afinidad por las células tumorales, infectando células estén o no en división ${ }^{3}$. Se ha desarrollado un tipo de vector llamado "amplicón", el cual contiene múltiples secuencias repetidas, que conservando su potencial infectivo, no existe posibilidad de replicación y posee una elevada capacidad de transporte ${ }^{16}$.

\section{Pox virus}

Virus DNA de doble cadena, como el vaccinia virus. Este vector es capaz de facilitar la expresión de genes estimuladores de citokinas, las cuales poseen poder antitumoral. También pueden ser manipulados para expresar genes suicidas, manteniendo una expresión prolongada de sus productos ${ }^{4}$.

De la misma familia es el virus canaripox, identificado en aves, que es capaz de infectar células humanas sin producir alteraciones significativas locales o sistémicas, expresando los genes insertados durante largo tiempo. Por este motivo se está utilizando en ensayos clínicos, donde ha demostrado su capacidad para inhibir el crecimiento tumoral en murinos ${ }^{17}$.

\section{Vectores no virales}

Son modos de transferencia génica mediante medios físicos o químicos. Incluyen:

Cadenas de DNA: La inyección física de DNA es el método más simple de transferencia génica. El mecanismo por el cual las los genes se introducen en las células diana se conoce como transfección. El DNA transferido se trasloca al núcleo por mecanismos no bien definidos, expresándose de forma transitoria o permanente en función de su integración en el genoma del huésped. La transfección más eficaz se consigue en las células musculares estriadas, consiguiendo un efecto terapéutico por las proteínas sintetizadas, que liberadas al torrente circulatorio ejercen su efecto sistémico ${ }^{4}$.
Cubriendo el DNA con partículas de oro se ha conseguido incrementar la eficacia de la transfección, pudiendo incorporarse el DNA modificado incluso a células que no están en división. Se han realizado experimentos en animales con genes responsables de la síntesis de citokinas $^{18}$. El mecanismo por el que pudiera incorporarse a tumores como el de próstata sería similar al de la braquiterapia, aunque se precisan más investigaciones.

Liposomas: Son vesículas compuestas por una doble capa de fosfolípidos, donde pueden ser incluidas sustancias como fragmentos de DNA. Impiden la degradación del DNA tras la administración intratumoral o sistémica, hasta alcanzar la diana terapéutica. Cuando alcanza la célula diana, la cubierta lipídica se fusiona con la membrana de la célula tumoral, liberando directamente la cadena de DNA al citoplasma celular ${ }^{5,19}$. Puede transportar gran cantidad de material génico y transferirlo a varias células sin necesidad de unión a receptores específicos. No es tóxico y es mínimamente inmunogénico. Sin embargo es un modo poco eficaz de transferencia génica, ya que es aclarado de la circulación sistémica rápidamente, por lo que su uso queda restringido a la aplicación intralesional ${ }^{4}$. La inserción de polietilenglicol en la membrana lipídica dificulta el aclaramiento sistémico, pero disminuye su capacidad de unión a la superficie celular. Ha demostrado ser bastante seguro en estudios de fase 1 sobre transferencia de liposomas conteniendo el gen de la interleukina-2, inyectado en próstatas de pacientes con cáncer de próstata avanzado $^{20}$.

Se han diseñado vectores híbridos como el complejo adenovirus-liposoma, que intenta corregir las limitaciones que por separado presentan cada uno de ellos, resultando ser un vector con una alta tasa de transferencia ${ }^{20}$.

Complejos de polímeros de DNA: Son polímeros no lipídicos que forman complejos con el DNA, ayudando a su liberación intracelular ${ }^{21}$. Estos complejos son aclarados de la circulación rápidamente, posiblemente por la interacción con las proteínas circulantes, por lo que se han añadido moléculas como la polietilenamina, que dificulta 
este proceso y facilita la traslocación al núcleo 22 . estos vectores son mínimamente alergénicos y toxicidad limitada en vivo, habiéndose experimentado en tumores intracraneales ${ }^{23}$.

\section{Generalidades}

\section{APLICACIÓN CLÍNICA}

El cáncer de próstata es un tumor genéticamente inestable, que adquiriere alteraciones genéticas durante su proliferación. En general, estos cambios afectan a genes supresores de tumores (protooncogenes) o a genes promotores del crecimiento celular (oncogenes). Potenciales dianas de la terapia génica implicaría la corrección de estas alteraciones. Sin embargo, la amplia variedad de las aberraciones cromosómicas adquiridas, hacen esta labor sumamente dificultosa. Uno de los más interesantes es el oncogen bcl-2, que inhibe la apoptosis incluso en presencia de una copia normal de p53. Se encuentra sobreexpresado en el cáncer de próstata andrógeno-independiente, favoreciendo no sólo su crecimiento, sino también resistencia a la supresión hormonal, antineoplásicos ${ }^{24}$, etc.
Otro tipo de genes son los llamados genes supresores, implicados en la tumorogénesis. Los más importantes residen en los cromosomas 10q y 16q. Los genes PTEN o MMAC1 localizados en el cromosoma 10 regulan la motilidad celular y las interacciones con la matriz celular a través de la cascada de señales mediadas por la proteín kinasa B/Akt, relacionada con el cáncer de próstata avanzado ${ }^{25}$. Existen otros genes supresores tumorales implicados en el cáncer de próstata, como el gen del retinoblastoma (cromosoma 13), mutado o deleccionado en el 35\% de los tumores de próstata avanzados, el gen KAI1 (cromosoma 11), los genes p53 y nm23 (cromosoma 17). En la Tabla 1 observamos las alteraciones más frecuentes correspondientes a oncogenes y genes supresores $^{26}$.

Otras potenciales dianas terapéuticas en la terapia génica son las moléculas de adhesión celular como cadherinas y caterinas, cuya expresión deficiente se ha relacionado con el cáncer de próstata. Factores de crecimiento como el IGF-1, con capacidad para activar el receptor androgénico en ausencia de andrógenos ${ }^{5}$.

Tabla 1. Alteraciones genéticas más comunes en el cáncer de próstata

\begin{tabular}{|c|c|c|c|}
\hline Gen & $\begin{array}{l}\text { Efecto en } \\
\text { tumorogénesis }\end{array}$ & Función del gen normal & Otros \\
\hline ras & Oncogen & $\begin{array}{l}\text { Regula la replicación del ADN } \\
\text { durante el ciclo celular }\end{array}$ & Mutado en $2-5 \%$ de ca próstata \\
\hline bcl-2 & Oncogen & $\begin{array}{l}\text { Interfiere con la vía de la p53 } \\
\text { inhibiendo la apoptosis }\end{array}$ & $\begin{array}{l}\text { Elevado en la mayoría de ca próstata. } \\
\text { andrógeno independientes y avanzado }\end{array}$ \\
\hline c-myc & Oncogen & $\begin{array}{l}\text { Regula la reparación del ADN } \\
\text { y la proliferación celular }\end{array}$ & $\begin{array}{l}\text { Puede estar implicado en la progresión } \\
\text { tumoral. }\end{array}$ \\
\hline GST-P1 & Gen supresor & $\begin{array}{l}\text { Detoxificante de posibles } \\
\text { carcinogénos }\end{array}$ & $\begin{array}{l}\text { La más común de las alteraciones } \\
\text { cromosómicas. Se halla en el } 98 \% \text { de los } \\
\text { pacientes. }\end{array}$ \\
\hline p53 & Gen supresor & $\begin{array}{l}\text { Detiene el ciclo celular en respuesta } \\
\text { al daño de ADN. También interviene } \\
\text { en la apoptosis celular. }\end{array}$ & $\begin{array}{l}\text { Su mutación se asocia con la progresión } \\
\text { andrógeno independiente. }\end{array}$ \\
\hline p21 & Gen supresor & $\begin{array}{l}\text { Control del ciclo celular y vía de la } \\
\text { apoptosis. }\end{array}$ & Suprime células tumorales in vitro \\
\hline p16 & Gen supresor & $\begin{array}{l}\text { Se une e inhibe a cdk } 4 \text {, regulando el } \\
\text { ciclo celular }\end{array}$ & Inhibe el crecimiento de células tumorales \\
\hline Retinoblastoma & Gen supresor & Regulación del ciclo celular & $\begin{array}{l}\text { Pérdida de un alelo en el } 27 \% \text { de los } \\
\text { tumores. }\end{array}$ \\
\hline E-cadherina & Gen supresor & Molécula de adhesión celular & $\begin{array}{l}\text { Disminuida o ausente en el } 50 \% \text { de los } \\
\text { tumores. Su valor normal se relaciona con } \\
\text { tumores. }\end{array}$ \\
\hline C-cam 1 & Gen supresor & Molécula de adhesión celular & $\begin{array}{l}\text { Disminuido en algunos tumores. Inhibe el } \\
\text { crecimiento del ca. próstata en animales. }\end{array}$ \\
\hline
\end{tabular}


Osteocalcina, presente en células epiteliales prostáticas. Enzimas como la glutation S transferasa, que se encuentra inactivada en el cáncer de próstata y es la encargada de la detoxificación de carcinógenos, por lo que su alteración podría facilitar los daños al DNA y el proceso de carcinogénesis. También genes que incrementen la inmunogenicidad del tumor, lo que provocaría una respuesta inmune eficiente por parte del organismo.

\section{ESTRATEGIAS TERAPÉUTICAS EN EL CÁNCER DE PRÓSTATA: DIANAS TERAPÉUTICAS}

\section{Favorecer la apoptosis}

El gen p53 ha sido uno de los más estudiados, observándose alterado en el 25-75\% de los cánceres de próstata. Interviene en la regulación de la interfase G1-S del ciclo celular, permitiendo la reparación del DNA dañado antes de la replicación y regula la muerte celular programada (apoptosis). La mutación de la p53, provoca una expansión clonal de las células con copias anómalas, progresión y metástasis ${ }^{27}$. Los estudios actuales valoran la eficacia de la transfección intraprostática de p53 en adenovirus, como ya ha demostrado in vitro ${ }^{28}$.

También se ha conseguido inducir apoptosis mediante la transferencia del gen de la caspasa 7 mediante un vector tipo adenovirus. La caspasa 7 se activa mediante proteolisis durante el proceso de la apoptosis. La sobreexpresión del gen de la caspasa es capaz de inducir apoptosis incluso en presencia de un inhibidor como es el encogen bcl-2.

\section{Genes suicidas}

Suelen consistir en genes que codifican enzimas que convierten un fármaco a su forma activa, con el objetivo de detener el ciclo celular y provocar la muerte de la célula tumoral respetando a la célula huésped, ya que la máxima concentración del metabolito activo queda circunscrito al tejido tumoral. Actualmente existen dos tipos de terapias con genes suicidas en investigación, el sistema herpes virus timidina kinasa (HSV-TK) y el de la Escherichia coli citosina de aminasa.

El sistema HSV-TK utilizando un adenovirus como vector, tiene una gran capacidad de fosfori- lación del ganciclovir, produciendo un metabolito tóxico incapaz de atravesar la membrana celular, provocando su muerte. En ensayos clínicos ha demostrado su eficacia, prolongando el tiempo de duplicación del PSA con pocos efectos secunda$\operatorname{rios}^{29}$.

El gen de la citosina deaminasa, ausente en células de mamíferos, expresa una enzima capaz de transformar citosina en uracilo. Al inyectar el profármaco 5 fluorocistina lo transforma en el metabolito activo 5 fluorouracilo, que inhibe la sintesis de DNA y RNA, induciendo muerte celular con mayor eficacia que el sistema HSV-TK ${ }^{5}$.

\section{Aumentar la respuesta inmune}

Aunque algunos tumores expresan antígenos que podrían ser reconocidos por el sistema inmune, no existe una respuesta eficaz del organismo a la proliferación de células tumorales ${ }^{30}$. Se ha reconocido en muchos tumores incluido el $\mathrm{CP}^{31}$, una expresión reducida o ausente del complejo mayor de histocompatibilidad $(\mathrm{CMH})$ tipo $1 \mathrm{y}$ moléculas adyuvantes como la B7, lo que disminuye la presentación de antígenos a los linfocitos $\mathrm{T}$ citotóxicos. Un incremento de la respuesta inmune tendría una serie de ventajas teóricas, como la ausencia de toxicidad, potencial acción contra las metástasis y memoria inmunogénica eficaz ante recidivas ${ }^{30}$.

De los dos tipos de respuesta inmune, humoral y celular, ésta última ha sido la más estudiada, centrándose fundamentalmente en los linfocitos $\mathrm{T}$ citotóxicos (CD8+). De forma simplificada podemos decir que un antígeno tumoral es una proteína que es liberada por la célula tumoral de forma natural o tras una terapia que provoque lisis celular. Estos antígenos son procesados por células encargadas de la respuesta inmune inespecífica (células presentadoras de antígenos) y presentados al linfocito $\mathrm{T}$ CD8+ en presencia del $\mathrm{CMH}$ tipo 1 y moléculas estimuladoras como las B7. También son presentados a los linfocitos $\mathrm{T}$ colaboradores (CD4+) en presencia del CMH tipo 2 , liberándose citocinas. De este modo se activa una respuesta inmune específica que tiene su eje fundamental en el linfocito T CD8+. Cualquiera de estos pasos es susceptible de ser diana de la terapia génica. 
Tabla 2. Ensayos clínicos con terapia génica in situ para pacientes con cáncer de próstata

\begin{tabular}{|c|c|c|c|c|c|}
\hline Institución & $\begin{array}{l}\text { Investigadores } \\
\text { Principales }\end{array}$ & Vector & Gen & Fase & País \\
\hline $\begin{array}{l}\text { Vanderbilt University School } \\
\text { of Medicine }\end{array}$ & Holt y Steiner & Retrovirus & $\begin{array}{l}\text { ARN myc } \\
\text { antisentido }\end{array}$ & I & U.S \\
\hline $\begin{array}{l}\text { Baylor College of Medicine, } \\
\text { Memorial Sloan-Kettering } \\
\text { Cancer Center }\end{array}$ & $\begin{array}{l}\text { Scardino y } \\
\text { Thompson }\end{array}$ & Ad serotipo 5 & HVS-tk cDNA & I & U.S \\
\hline $\begin{array}{l}\text { University of California, } \\
\text { Los Angeles }\end{array}$ & Belldegrum & $\begin{array}{l}\text { Complejo catiónico } \\
\text { Liposomas/DMRI- } \\
\text { DOPE }\end{array}$ & IL-2 cDNA & I & U.S \\
\hline $\begin{array}{l}\text { Mount Suinai School of } \\
\text { Medicine }\end{array}$ & Hall y Woo & Ad serotipo 5 & HVS-tk cDNA & I & U.S \\
\hline $\begin{array}{l}\text { University of California, } \\
\text { Los Angeles }\end{array}$ & Belldegrum & Ad serotipo 5 & p53 cDNA & I & U.S \\
\hline $\begin{array}{l}\text { The University of Texas MD } \\
\text { Anderson Cancer Center }\end{array}$ & Logothetis & Ad serotipo 5 & p53 cDNA & I-II & U.S \\
\hline Baylor College of Medicine & Kadmon y Thompson & Ad serotipo 5 & HVS-tk cDNA & I-II & U.S \\
\hline Johns Hopkins University & Simons & Ad serotipo 5 & $\begin{array}{l}\text { Promotor y } \\
\text { facilitador } \\
\text { de elementos } \\
\text { de PSA }\end{array}$ & I & U.S \\
\hline $\begin{array}{l}\text { University of Virginia Health } \\
\text { Science System }\end{array}$ & Gardner y Chang & Ad serotipo 5 & SHV-tk cDNA & I & U.S \\
\hline $\begin{array}{l}\text { University of California, } \\
\text { Los Angeles }\end{array}$ & Belldegrum & $\begin{array}{l}\text { Complejo catiónico } \\
\text { liposomas }\end{array}$ & IL-2 cDNA & II & U.S \\
\hline Henry Ford Health System & Freytag y Kim & Ad serotipo 5 & & I & U.S \\
\hline Baylor College of Medicine & Butler y Aguilar & Ad serotipo 5 & HVS-tk cDNA & I-II & U.S \\
\hline $\begin{array}{l}\text { University of Tennessee, } \\
\text { Coleman College of Medicine }\end{array}$ & Gingrich & Ad serotipo 5 & p16 cDNA & I & U.S \\
\hline $\begin{array}{l}\text { Stanford University Palo Alto } \\
\text { Veterans Administration } \\
\text { Medical Center }\end{array}$ & Terris & $\begin{array}{l}\text { Ad serotipo 5/ } \\
\text { replicación } \\
\text { competente }\end{array}$ & $\begin{array}{l}\text { Elementos } \\
\text { PSA }\end{array}$ & $\mathrm{I}-\mathrm{II}$ & U.S \\
\hline $\begin{array}{l}\text { University of California, } \\
\text { Los Angeles }\end{array}$ & Belldegrum & $\begin{array}{l}\text { Complejo catiónico } \\
\text { Liposomas/ } \\
\text { DMRI-DOPE }\end{array}$ & IL-2 cDNA & I-II & U.S \\
\hline $\begin{array}{l}\text { The University of Texas } \\
\text { MD Anderson Cancer Center }\end{array}$ & Pollack & Ad serotipo 5 & p53 cDNA & II & U.S \\
\hline $\begin{array}{l}\text { Indiana University Medical } \\
\text { Center }\end{array}$ & Gardner & Ad serotipo 5 & $\begin{array}{l}\text { Promotor } \\
\text { osteocalcina }\end{array}$ & I & U.S \\
\hline Henry Ford Health System & Freytag y Kim & Ad serotipo 5 & & I & U.S \\
\hline Baylor College of Medicine & Milers y Thompson & Ad serotipo 5 & IL-2 cDNA & I & U.S \\
\hline Johns Hopkin University & De Weese & Ad serotipo 5 & $\begin{array}{l}\text { Promotor y } \\
\text { facilitador de } \\
\text { elementos de PSA }\end{array}$ & II & U.S \\
\hline Henry Ford Health System & Freytag y Kim & Ad serotipo 5 & SHV-tk cDNA & I & U.S \\
\hline $\begin{array}{l}\text { Okayama University } \\
\text { School of medicine }\end{array}$ & Kumon & Ad serotipo 5 & SHV-tk cDNA & I & Japón \\
\hline $\begin{array}{l}\text { Erasmus University } \\
\text { Noruega }\end{array}$ & Bangma & Ad serotipo 5 & SHV-tk cDNA & I & \\
\hline $\begin{array}{l}\text { Universidad Autónoma } \\
\text { de Nuevo León }\end{array}$ & Rojas-Martínez & Ad serotipo 5 & SHV-tk cDNA & $\mathrm{I}-\mathrm{II}$ & Méjico \\
\hline $\begin{array}{l}\text { Kobe University School } \\
\text { of medicine }\end{array}$ & Gotoh & Ad serotipo 5 & $\begin{array}{l}\text { Promotor } \\
\text { osteocalcina }\end{array}$ & I-II & Japón \\
\hline
\end{tabular}


Una atención especial se ha centrado en el uso de vacunas mediante factores estimuladores de colonias de macrófagos y granulocitos (GM-CSF), interleukinas 2, 4, 6, 7 y 12, factor de necrosis tumoral alfa e interferones beta y gamma autólogos $^{4}$. El GM-CSF puede ser transferido mediante vectores virales a células tumorales autólogas o alogénicas exvivo, posteriormente se inyecta la próstata y es capaz de estimular a células presentadoras de antígenos iniciándose una respuesta inmune específica. Respecto a otras citocinas como la IL2 intratumoral, utilizando como vehículo un plásmido, logra disminuir los niveles de PSA en el $80 \%$ de los pacientes a las 2 semanas $^{32}$. Otra posibilidad es la vacuna de DNA, mediante la cual se transfiere un transgen contra el cual queremos elicitar la respuesta inmune, habiendo conseguido buenos resultados en animales $^{33}$. Las principales limitaciones de este tipo de terapia son la cantidad de tumor que puede ser eliminado (está limitado a tumores pequeños) y el coste técnico y económico de estas terapias.

En la Tabla 2 quedan descritos los ensayos que se están desarrollando mediante terapia génica in situ para pacientes con cáncer de próstata $^{34}$.

\section{Vacunas basadas en células dendriticas}

Las células presentadoras de antígenos más potentes del sistema inmunitario son las células dendríticas las cuales desempeñan una función central en la inducción de respuestas inmunes contra antígenos tumorales. Estas células presentan una habilidad excepcional para estimular tanto linfocitos $\mathrm{T}$ citotóxicos como linfocitos $\mathrm{T}$ colaboradores debido a su capacidad para, por un lado, captar y presentar antígenos en el contexto apropiado de los MHC I y II, y por otro para secretar citokinas y expresar niveles elevados de otras moléculas coestimuladoras como CD80 y CD86. Debido a sus características y a la facilidad para generarlas en el laboratorio a partir de monocitos de sangre periférica en presencia de determinadas citokinas, las células dendríticas aparecen en un gran número de estudios como base para generar vacunas cuya eficacia se ha estudiado en modelos animales y en ensayos clínicos en los que además se ha demostrado una excelen- te tolerancia por parte de los pacientes. La inmunoterapia con estas células puede usarse de forma complementaria a otros tratamientos ó constituir una alternativa a los mismos. Las estrategias se orientan en general a estimular la proliferación de las células dendríticas con capacidad específica antitumoral, a aumentar su capacidad de captar y presentar antígenos o bien se dirigen a proveer células dendríticas transducidas con el antígeno(s) de interés. En el cáncer de próstata hay más de 50 trabajos que demuestran la seguridad de estas vacunas desde un punto de vista clínico, si bien la mayoría de los ensayos clínicos se encuentran en fases iniciales (34). Algunos ejemplos los encontramos en el uso de células dendríticas transducidas con los genes de antígenos tumorales como PSA o PSMA, con ARN mensajero bien específico (como es el caso del de la telomerasa) o bien proveniente de tumor completo, y también en estudios en los que las células dendríticas se han incubado con lisado tumoral completo o con péptidos específicos ${ }^{35-8}$. En general los distintos abordajes van dirigidos a estimular una respuesta inmunitaria específica contra el tumor que redunde en un beneficio clínico apreciable y que pueda suponer en última instancia la curación del paciente. Los resultados hasta el momento son transitorios, modestos pero prometedores porque son similares a los de la quimioterapia pero, como hemos dicho antes, la tolerancia es excelente ${ }^{39-45}$.

\section{CONCLUSIONES}

Estamos asistiendo a los inicios de una nueva y prometedora modalidad de tratamiento en la lucha contra el cáncer. Actualmente, la vacunación en el cáncer de próstata, aunque experimental, es posible, es segura y su eficacia semejante a la que brinda la quimioterapia. El futuro de la terapia génica como opción terapéutica real, va a depender del desarrollo de nuevos vectores y de los avances en el conocimiento de la biología molecular de esta enfermedad. A pesar de las limitaciones técnicas y económicas, es de esperar que los nuevos ensayos de terapias combinadas con hormonoterapia, quimioterapia y radioterapia, continúen el camino hacia la curación del cáncer de próstata. 


\section{REFERENCIAS}

1. Landis S, Murray T, Bolden S, Wingo P. Cancer statistics. Cancer J Clin. 1999; 49(1):8-31.

2. Visakorpi T, Kallioniemi AH, Syvänen AC, Hyytinen ER, Karhu R, Tammela T et al. Genetic changes in primary and recurrent prostate cancer by comparative genomic hybridation. Cancer Res. 1995;55(2):342-347.

3. Shalev M, Timothy C, Kadmon D, Ayala G, Kernen K, Miles B. Gene therapy for prostate cancer. Urology 2001;57(1):8-16.

4. Harrington K, Spitzweg A, Bateman J, Morris J, Vile R. Gene therapy for prostate cancer: current status and future prospects. J Urol. 2001;166(4):12201223.

5. Mazhar D, Waxman J. Gene therapy for prostate cancer. BJU International 2004;93(4):465-469.

6. Krasnysh V, Mikheeva G, Douglas J. Generation of reconbinant adenovirus vectors with modified fibers for altering virl tropism. J Virol. 1996;70(10):68396842

7. Coffey M, Strong J, Forsyth P. Retrovirus therapy of tumors with activated Ras pathway. Science 1998;282 (5392):1332-1334.

8. Schirrmacher V, Haas C, Bonifer R. Human tumor cell modification by virus infection: an efficient and safe way to produce cancer vaccine with pliotropic immune stimulatory properties when using Newcastle disease virus. Gene Ther. 1999;6(1):63-73.

9. Palapattu G, Naitoh J, Belldegrun A. Gene therapy for prostate cancer. Urol Clin North Am 1999;26:353-363

10. Naldini L, Blomer U, Gallay P. In vivo gene delivery and stable transduction of non dividing cells by a lentiviral vector. Science 1996;272(5259):263-267.

11. Zhang W. Development and application of adenoviral vectors for gene therapy of cancer. Cancer Gene Ther. 1999;6 (2):113-138.

12. Dai Y, Schwarz E, Gu D, Zhang W, Sarvetnick N, Verma I. Cellular and humoral responses to adenoviral vectors containing factor IX gene: telorization of factor IX and vector antigens allows for long-term expresion. Proc Natl Acad Sci USA 1995;92(5):1401-1405

13. Hay R. The origin of the adenovirus DNA replication: minimal DNA secuence requirement in vivo. EMBO J 1985; 4(2):421-426.

14. Paielli D, Wing M, Rogulski K. Evaluation of the biodistribution, persistence, toxicity and potential of germ-line transmission of a replication-competent human adenovirus following intraprostatic administration in the mouse. Mol Ther. 2000;1(3):263-274.

15. Vieweg J, Boczkowski D, Roberson KM, Edwards DW, Philip M, Philip R et al. Efficient gene transfer with adeno-associated virus-based plasmids complexed to cationic liposomes for gene therapy of human prostate cancer. Cancer Res. 1995;55 (11):2366-2372.

16. Sena-Esteves M, Saeki Y, Fraefel C, Breakefield XO. HSV-1 amplicon vector: simplicity and versatility. Mol Ther. 2000;2(1):9-15.

17. Siemens DR, Austin JC, Hedican SP, Tartaglia J, Ratliff TL. Viral vector delivery in solid-state vehicles: gene expresion in a murine prostate cancer model. J Natl Cancer Inst. 2000;92(5):403-412.

18. Prince H. Gene transfer: a review of methods and applications. Pathology 1998;30(4):335-347.

19. Gao X, Huang L. Cationic liposome-mediated gene transfer. Gene Ther. 1995; 2(10):710-722

20. Cotten M, Wagner E, Zatloukal K, Phillips S, Curiel DT, Birnstiel ML. High-efficiency receptor-mediated delivery of small and large (48 kilobase gene constructs using the endosome-disruption activity of defective or chemically inactivated adenovirus particles. Proc Natl Acad Sci. U S A 1992;89(13):6094-6098.

21. Li S, Huang L. Non viral gene therapy: promises and challenges. Gene Ther 2000; $7(1): 31-34$

22. Godbey W, Wu K, Mikos A. Tracking the intracellular path of poly(ethylenimine)/DNA complexes for gene delivery. Proc Natl Acad Sci. USA 1999;96(9): 51775181

23. Goldman CK, Soroceanu L, Smith N, Gillespie GY, Shaw W, Burgess S et al. In vitro and in vivo gene delivery mediated by a synthetic polycationic amino polymer. Nat Biotechnol. 1997;15(5):462-466.

24. DiPaola RS, Aisner J. Overcoming bcl-2- and p53-mediated resistance in prostate cancer. Semin Oncol. 1999;26 (1Suppl2):112-116.

25. Suzuki H, Freije D, Nusskern DR, Okami K, Cairns P, Sidransky D et al Interfocal heterogeinity of PTEN/ MMACC 1 gene alterations in multiple metastatic prostate cancer tissues. Cancer Res. 1998;58(2):204-209.

26. Eder IE, Haag P, Bartsch G, Klocker H. Gene Therapy strategies in prostate can cer. Current Gene Therapy 2005; 5(1):1-10.

27. Asgari K, Sesterhenn IA, McLeod DG, Cowan K, Moul JW, Seth P, et al. Inhibition of the growth of pre-established subcutaneous tumor nodules of human prostate cancer cells by single injection of the recombinant adenovirus p53 expression vector. Int J Cancer 1997;71(3):377-382.
28. Ko SC, Gotoh A, Thalmann GN, Zhau HE, Johnston DA, Zhang WW et al Molecular therapy with recombinant p53 adenovirus in an androgen-independent metastatic humanprostate cancer model. Hum Gene Ther. 1996; 7(14):1683-1691.

29. Herman JR, Adler HL, Aguilar-Cordova E, Rojas-Martinez A, Woo S, Timme TL et al. In situ gene therapy for adenocarcinoma of the prostate: a phase I clinical trial. Hum gene Ther. 1999;10(7):1239-1249.

30. Melcher A, Gough M, Todryk S, Vile R. Apoptosis or necrosis for tumor immunotherapy: what's in a name? J Mol Med. 1999;77(12):824-829.

31. Kwon ED, Hurwitz AA, Foster BA, Madias C, Feldhaus AL, Greenberg NM et al Manipulation of $\mathrm{T}$ cell coestimulatory and inhibitory signals for immunotherapy of prostate cancer. Proc Natl Acad Sci. U S A 1997;94_(15):8099-8103.

32. Pantuk A, Zisman A, Belldegrun A. Gene therapy for prostate cancer at the University of California, Los Angeles: preliminary results and future directions. World J Urol. 2000;18(2):143-147.

33. Kim JJ, Trivedi NN, Wilson DM, Mahalingam S, Morrison L, Tsai A et al Molecular and inmunological analysis of genetic prostate specific antigen (PSA) vaccine. Oncogene 1998;17(24):3125-3135.

34. Rini B. Recent clinical development of dendritic cell-based immunotherapy for prostate cancer. Expert Opin Biol Ther. 2004;(11):1729-1734

35. Machlenkin A, Paz A, Bar Haim E, Goldberger O, Finkel E, Tirosh B, Volovitz I, Vadai E, Lugassy G, Cytron S, Lemonnier F, Tzehoval E, Eisenbach L.Human CTL epitopes prostatic acid phosphatase- 3 and six-transmembrane epithelial antigen of prostate- 3 as candidates for prostate cancer immunotherapy. Cancer Res. 2005;65(14):6435-6442.

36. Su Z, Dannull J, Yang BK, Dahm P, Coleman D, Yancey D, Sichi S, Niedzwiecki D, Boczkowski D, Gilboa E, Vieweg J.Telomerase mRNA-transfected dendritic cells stimulate antigen-specific CD8+ and CD4+ T cell responses in patients with metastatic prostate cancer. J Immunol. 2005;174(6):3798-3807.

37. Mu LJ, Kyte JA, Kvalheim G, Aamdal S, Dueland S, Hauser M, Hammerstad H, Waehre H, Raabe N, Gaudernack G. Immunotherapy with allotumour mRNAtransfected dendritic cells in androgen-resistant prostate cancer patients. $\mathrm{Br} J$ Cancer. 2005;93(7):749-756.

38. Satoh T, Irie A, Egawa S, S. B. In situ gene therapy for prostate cancer. Current Gene Therapy. 2005;(1):111-119.

39. Mu LJ, Kyte JA, Kvalheim G, Aamdal S, Dueland S, Hauser M, Hammerstad H, Waehre H, Raabe N, Gaudernack G. Immunotherapy with allotumour mRNAtransfected dendritic cells in androgen-resistant prostate cancer patients. $\mathrm{Br} J$ Cancer. 2005;93(7):749-756

40. Pandha HS, John RJ, Hutchinson J, James N, Whelan M, Corbishley C, Dalgleish AG. Dendritic cell immunotherapy for urological cancers using cryopreserved allogeneic tumour lysate-pulsed cells: a phase I/II study. BJU Int 2004;(3):412-418.

41. Small EJ, Schellhammer PF, Higano CS, Redfern CH, Nemunaitis JJ, Valone FH, Verjee SS, Jones LA, Hershberg RM. Placebo-controlled phase III trial of immunologic therapy with sipuleucel-T (APC8015) in patients with metastatic, asymptomatic hormone refractory prostate cancer. J Clin Oncol 2006;24(19):3089-3094

42. Hildenbrand B, Sauer B, Kalis O, Stoll C, Freudenberg MA, Niedermann G, Giesler JM, Juttner E, Peters JH, Haring B, Leo R, Unger C, et al Immunotherapy of patients with hormone-refractory prostate carcinoma pretreated with interferon-gamma and vaccinated with autologous PSA-peptide loaded dendritic cells-A pilot study. Prostate. 2007;67(5):500-508

43. Waeckerle-Men Y, Uetz-von Allmen E, Fopp M, von Moos R, Bohme C, Schmid HP, Ackermann D, Cerny T, Ludewig B, Groettrup M, Gillessen S. Dendritic cellbased multi-epitope immunotherapy of hormone-refractory prostate carcinoma Cancer Immunol Immunother. 2006:55(12):1524-1533.

44. Thomas-Kaskel AK, Zeiser R, Jochim R, Robbel C, Schultze-Seemann W, Waller $\mathrm{CF}$, Veelken H. Vaccination of advanced prostate cancer patients with PSCA and PSA peptide-loaded dendritic cells induces DTH responses that correlate with superior overall survival. Int J Cancer. 2006;(10):2428-2434.

45. Fuessel S, Meye A, Schmitz M, Zastrow S, Linne C, Richter K, Lobel B, Hakenberg OW, Hoelig K, Rieber EP, Wirth MP. Vaccination of hormone-refractory prostate cancer patients with peptide cocktail-loaded dendritic cells: results of a phase I clinical trial. Prostate. 2006 Jun 1;66(8):811-821.

Correspondencia autor: Dr. L. Gómez Pérez

Servicio de Urología. Hospital General Universitario de Elche Camí de l'Almassera, 11. 03203 Elche (Alicante) Tel.: 966679000

E-mail autor: luisgope@hotmail.com

Información artículo: Revisión - Vacuna en cáncer de próstata

Trabajo recibido: abril 2007

Trabajo aceptado: mayo 2007 